\title{
Parallel Processes: Getting it Write?
}

Ruth Emond, University of Stirling

Laura Steckley, University of Strathclyde

Autumn Roesch, University of Stirling

\section{Accepted for publication in Journal of Social Work published by Taylor and Francis.}

\begin{abstract}
This paper offers a critical reflection on the processes surrounding the writing of a book aimed at foster carers and residential workers. By utilising the concept of parallel process as well as the four modes of reflection identified by Ruch (2000), we explore the ways in which the wider context of both direct work with children and reflective practice have been impacted by the tensions between relationally based, child-centred practice and wider managerialist imperatives. The paper draws parallels between these practice tensions and those currently in play within the academy. By employing a dialogical and reflective analysis of the process and interactions surrounding the writing of a practitioner-targeted book, the paper demonstrates the ways in which critical and process reflection post event took place, considering the heretofore unexplored parallel processes between writing for practice, and practice. In so doing, it identifies the ways in which the authors mirrored practitioners in relation to the management of anxiety, a sense of constrained autonomy and confidence, and an avoidance of recognising and challenging structural and political context. Implications for the creation of practice literature and for the academy are considered.
\end{abstract} (187 words) 
Key words: parallel process, writing for practice, relationship, containment, voice 


\section{Introduction}

The idea that children should be at the centre of decision making, assessment and intervention has become an established tenet of social work and social care practice (Turney, Platt, Selwyn \& Farmer, 2011) and related policy (Munro, 2011; Scottish Government, 2014; HM Government, 2015). Allied to such an approach is the belief that this is best achieved through relationship-based practice (Howe, 1998; Trevithick, 2003; Winter, 2010). Thus, workers and carers, in their unique connection to the child, are regarded as pivotal to change occurring. Whilst the efficacy of this is well established, and indeed is supported by the authors of this paper, it emphasises the worker/carer relationship as the central agent of change, arguably obscuring the structural, social and environmental forces that may be at play (Featherstone, 2016). Change is expected from the individual actors: the child, carer, parent and workers, rather than the wider context in which they operate (Bywaters et al., 2015).

A parallel direction of travel is evident in academia. In the social sciences, there has been an increasing move toward evidencing the applied nature of research work (Davies, Nutley \& Walter, 2005). Its usefulness to wider society has become a key feature of what is valued by the academy and is now a central requirement of funding awards (Morton, 2014). Researchers are expected to identify and produce useful resources, which have a measureable impact. They should, at least in part, engage with and be motivated by a sense of responsibility to society in its broadest sense, and despite the often wider structural reasons for difficulties, create measureable change (Pardoe, 2014).

This paper explores the contradictions and challenges inherent in writing a 'useful' practice orientated book and what can be learned from them. In it we 
argue that practice and academia have come to a similar contradictory crossroads. Drawing on the concept of parallel process, we critically reflect on the process of writing a book aimed at carers and practitioners working with looked after children and young people under the demands of the Research Assessment Framework (REF) ${ }^{1}$. By using the writing of the book as the unit of analysis we employ aspects of a reflective methodology to explore our experience of straddling the tensions between the child at the centre and the wider context, as played out in the writing of an applied text in the era of externally evaluated and measured scholarship. While we assume other writers will have had at least some similar reflections, this paper adds to the body of existing literature by exposing some of the 'backstage' (Goffman, 1956) processes and considerations as a means of opening up dialogue and shared insight related to these tensions. Moreover, we offer them not only to demonstrate some of the parallel processes between direct practice and practice-related academic writing, but to argue that by illuminating these processes, their deleterious effects can be mitigated and their enhancing potential harnessed in order to improve their impact.

The paper begins by outlining the premise for the book and the approach taken to writing it. It goes on to discuss the critical reflection that took place during, but mostly following, the book's publication. In so doing it employs aspects of Ruch's (2000) modes of reflection as well as the concept of parallel process. Finally, it discusses the four key themes emerging from the analysis: relational processes, past relationships, hope and voice.

\section{Background}

\footnotetext{
${ }^{1}$ The Research Assessment Framework (REF) is used to assess the quality of research across all higher education institutions in the UK.
} 
The idea for the book came from a number of discussions we had had over a period of years around looked after children and their day-to- day care experience. We wanted to use learning derived from a synthesis of our respective research, scholarship and practice to offer a different approach to practice literature. Arguably, in the existing literature there appeared to be a tension between recognising and working with the symptoms of past 'trauma' whilst at the same time holding on to both 'normal' developmental behaviours or responses, as well as the current events or experiences that the children are exposed to (Ward, 2006). We considered that there was a space for a book that tried to bridge the theoretical and practice gap and which encouraged direct carers to hold a range of hypotheses (rather than a potentially pathologising diagnosis) in mind when trying to make sense of the children they were looking after.

We were also committed to addressing the impact of caring work on carers, as well as their related needs. As a result, we hoped the book would serve as a form of containment insofar as it might become a resource for helping carers 'make sense of what is going on' (Schofield, 1998, p.65) - not only what might be going on with the child or young person, but also what may be happening within themselves. While we spoke explicitly about the parallels between some of the adult-focused and child-focused content of the book, our considerations of the parallels between our own processes and the thinking and practicing we were encouraging in carers was less evident to us during the writing process.

During the writing of the book, we met regularly as a three to discuss ideas, track progress and comment on each other's contributions. More often than not, the writing and discussion reconnected us to children with whom we were either currently working or had worked with in the past. By writing and talking reflectively about these children it allowed for our thinking to slow down (Shahjahan, 2015). We began to unpick and re-examine in more detail our 
thoughts and actions as practitioners and to re-evaluate our previous and current direct practice work. Alongside this, many of our meetings included sharing current experiences in academia, comparing the policies and expectations of our employing universities, as well as the wider debates within the academy - particularly around writing and publishing.

Following the publication of the book we continued this process of reflection, both individually and as a group. We began to think more analytically about the process of writing and what had impacted on the choices we had made in terms of audience, content and style. This paper arose from these discussions we had as co-authors about the experience of writing together and how the process played out. By looking systematically at the experience of writing for and about practice, we argue that many of the current tensions experienced in both practice and academia are part of a parallel process that warrants closer scrutiny.

\section{Method}

By identifying the themes emerging from our experiences we were able to link these to the literature on parallel process, relationships and reflexivity to '... widen our repertoire of interpretation (Alvenson \& Skoldberg 2009, p.2727) to incorporate insights beyond our experience and the initial account generated ...' (Hodgson \& Watts, 2016 p.6). We drew on the four modes of reflection identified by Ruch (2000) to reconsider our experiences. These include: technical reflection, or reflection using external or technical sources to solve problems; practical reflection, or reflection that encourages dialogue to explore meaning making, challenge assumptions, identify alternatives and enhance understanding; critical reflection, or reflection that comprises the previous two modes but also incorporates consideration of structural 
conditions that promote privilege and constrain practice; and process reflection, or reflection that emphasises the emotional content of interactions and its unavoidable impact on practitioners (Ruch, 2000, pp. 101-102). We employed these lenses to both individually and in dialogue explore the following: what the experience of writing had been for us; what some of the dynamics had been in our process; how we thought those dynamics might have affected the book; how we thought we had used that time; and how our experiences compared to other writing that we had been involved in.

It was clear that there were common themes emerging from these discussions, both in terms of content as well as process. These were confirmed in a review and thematic analysis of the notes of the meetings kept during the development and writing of the book and the topics these meetings covered. Four key themes emerged:

1. The relational nature of writing for practice: putting processes to the fore

2. The importance of past relationships: ghosts and invisible forces

3. Hope and hopelessness: The systemic issues facing children over which there seems little control

4. Voice: The legitimacy of our claims and experiences in relation to the book

Through this process, we acknowledged the impact that not only the writing, but perhaps more significantly talking and reflecting, had had on each of us. We wondered about the extent to which we had been mirroring many of the feelings and actions experienced by 
those currently caring for children. Equally, we began to consider the extent to which the effects of certain academic processes were being unconsciously represented in our approach to writing, our feelings about what was being produced, and perhaps most importantly, the impact this might have had on our book. Whilst reflecting on this, the application of the theory of parallel process to our critical analysis was revelatory.

\section{Parallel process as a theoretical construct}

Parallel process has its origins in the revisiting of psychoanalytic thinking in the late 1950s. Primarily, it was used as a way of understanding the transference and counter transference that was occurring in the psychotherapeutic supervisory relationship. One of the first to identify this as not only a phenomenon but as a useful resource for supervisors was Searle (1955). Initially referring to it as a reflection process he suggested that '... processes at work currently in the relationship between patient and therapist are often reflected in the relationship between therapist and supervisor' (Searle 1955, p.135). Unlike transference and counter transference, parallel process refers to a '...mirroring of the current relationship in the here and now while countertransference is an 'as if' phenomenon' (Talbot 1990, p.2667).

The concept has also been explored in terms of what function it might serve. For some, it offers a process of communication when 'words cannot be used' (Morrisey \& Tribe 2001, p.105). Whilst for others, it draws attention to what may be being unconsciously concealed, more often than not as a result of deep anxiety (Bromberg, 1982). Many writers in this field identify the centrality of power differentials to this dynamic. Morrisey 
and Tribe suggest (p.105) ' ... essentially it [parallel process] involves intertwined concerns about authority and dependence whereby participants need to conceal their attempted solutions to such concerns'.

Those researching in the field of organisational cultures and learning have also employed parallel process as a concept to understand both the behaviour and dynamics occurring in the organisation, as well as their own roles as researchers in this context (Obholzer \& Roberts, 1994). Writers such as Storolow (1994) have extended the concept of parallel process to a broader acknowledgment of intersubjective dynamics. As such this intersubjective field in which actors are operating is a '... dynamic formula encompassing the observer, the observed and the system they inhabit' (Sullivan, 2002, p.379). According to this perspective, the experiences of those conducting research (and we would argue those writing for practice) are heavily influenced by the thoughts, actions and beliefs being transmitted by participants and by the organisational culture itself. Thus, it is argued that without critical reflection and external support, feelings and views become transferred from the researched to the researcher at an unconscious level and infiltrate the encounter and its subsequent analysis.

What appears to be shared between these theoretical approaches to parallel process are the powerful ways in which experiences and feelings belonging to group members are experienced and played out by others in the group. The context around this is crucial to interrogate as it suggests a dynamic of power and hierarchy and of potential anxiety and fear of exposure - all of which (in regards to this paper) holds the power to distort what gets written. Perhaps most importantly, it recognises what the parties bring to the encounter and the vital role that reflection plays in unpicking this process (Sullivan 2002, p.391). It is 
to our collective reflection and the themes generated that the remainder of this paper now turns.

\section{Findings and Discussion: Parallels in action}

By undertaking a systematic series of reflections and analysis of written records, four key themes repeatedly emerged. The following section presents these themes and uses Ruch's (2000) modes of reflection and the concept of parallel process to interrogate them further.

The relational nature of writing for practice: putting processes to the fore

Ward (2010) coined the term 'matching principle' to emphasise that, in order to effectively prepare students for practice, modes of learning must match modes of practice across all forms of professional education. Accordingly, the best learning about relationship-based practice happens within the context of learning relationships. Moreover, he suggests that equal emphasis must be placed on the process as well as the content of learning because both must be learned. Arguably, writing about relationship-based practice also requires a consideration of the relationships between writers and readers. Furthermore, writing which aims to support learning for practice must have a similar orientation, both in terms of its own content and the processes of bringing it to readers.

From the start, we shared an explicit commitment to actively avoid a procedural orientation to the book. We were well aware of the influence of managerialist, tick-box 
approaches to care practices (Munro, 2011; Smith, 2009), as Moss and Petrie (2002, p.11) clearly identify in children's services more widely:

...we live in a culture where we are constantly being offered solutions before we have asked the critical questions ... it seems all of us who work with children are increasingly expected to concentrate on universal, predetermined outcomes and methods for achieving these outcomes, pressing the right button, crowding out possibilities to think, question, understand, discuss, contest and reflect.

Alongside this, Ruch (2000) suggests that a central feature of good practice is the ability to acknowledge and hold onto uncertainty and the anxiety that this can generate. Containing spaces and relationships are needed to allow this uncertainty to be shared. We wanted carers to see some of their own experiences identified, named and affirmed, and in so doing, support them in being able identify and name other, previously semi-conscious and anxiety-provoking dimensions of their caring practices. We also wanted the book to invite readers to think not only about their practice in potentially new and different ways, but to think about their own thinking - a limited but urgently-needed capacity recently highlighted by Turney and Ruch (2016).

Making this possible posed a seemingly paradoxical challenge; locating theory in the forefront had the very real possibility of alienating at least some of our target audience. It was vital that we held in mind carers' potential experiences of the work, and of reading practice-related literature. We actively developed a relationship with imagined readers which informed many of our decisions about content and style until we could seek out feedback from actual carers in the latter stages of drafting. While consideration of an imagined reader is not 
new or uncommon, harnessing insights from the parallel processes at play adds substance to the effort; in our case, it might have highlighted blind spots that were revealed in the final stages (and even after) completing the book and which will be discussed below.

Arguably, this desire to connect, to provide the 'right' content and indeed nourishment to a known but unknown other is also played out in the care practices of residential and foster carers. Having to anticipate what is needed by a child, whilst at the same time being aware of what resources are available both internally and externally, is central to 'good' care. Using Ruch's ( $\left.\begin{array}{llll}2 & 0 & 0 & 0\end{array}\right)$ lens of critical reflection, it seemed that for many carers, like us as writers, there was often a foregrounding of 'doing' and 'producing' at the expense of deep thinking, preparation and careful planning. The pressure to respond quickly to children in crisis, to accept them into the home or residential centre, to get them 'involved' in the community makes such vital work even more challenging. Attention is often focused on 'settling' the child and getting practical steps in place (school placement, clothing), often at the expense of space and time to develop the relationships between carer and child, carer and referrer, referrer and family.

We also attended to our relationships with one another and spoke candidly about our experiences of writing. By employing process and practical reflection (Ruch 2000) we became retrospectively curious about the potential parallels between our relational processes and those espoused in the book. The parallels between educators' relationships and the impact on professional education has been highlighted (Ward, 2010); however, similar parallels have not been considered between practice-related writing and practice.. It seems intuitively obvious that relational processes which promote containment (Ruch, 2007) would be more facilitative of clear thinking and therefore effective writing than those which disrupt 
containment (e.g. poorly managed or unresolved conflicts, repression of differences). Likewise, our reflecting on and attendance to our own interpersonal processes (Ruch 2000) provided containment for the inherent challenges of writing,

Robust reflection, whether in relation to practice or writing, is significantly challenging. Ruch (2000) highlights how the privileging of doing over the thinking and feeling aspects of practice and professional education undermines practitioners' ability to reflexively hold in mind inner and outer worlds - their own, those of their clients and the relationship between the four. The implications of this are significant and can be linked to burnout and retention (Kinman \& Grant, 2011), the perpetuation of oppression (Frogget, Ramvi, \& Davies, 2015; Mandell, 2011); and even to catastrophic failures of child protection (Cooper, 2005). Similarly, this rush to 'produce' as opposed to attending to or contemplating a theoretical or applied position has come to dominate Higher Education. Amsler (2011) suggests that this extends to the limited value given to the essential elements required for critical and original thinking, including relationships and time.

The importance of past relationships: ghosts and invisible forces

Current relationships and the dynamics they engender, while complex and encompassing, constitutes only a portion of the parallel processes at play in practice-related writing. Doucet (2008) suggests that researchers have 'ghosts' that haunt their lives and work. The first of these, she suggests, is the 'gossamer wall' ' ... between the differing versions of ourselves, evolving through time, and the possible ghosts or 'shadow others' that may come to visit 
us' (Doucet 2008, p.76). These metaphorical ghosts of our former selves and of the children, families and colleagues with whom we had worked appeared to us throughout the writing of the book; we discussed them and what we had learned from them regularly. Only on reflection did we realize that they had in many ways been our guides and companions as well as uncomfortable reminders of the complexity of the caring role during the writing process. In this sense they had been essential in our efforts to ground our writing in the realities of practice.

Gordon (1996, p.8) argues that '... being haunted draws us affectively, sometimes against our will and always a bit magically, into a reality we come to experience, not as cold knowledge, but as transformative recognition'. These ghosts helped us to 'know' our imaginedreaders.. We repeatedly asked ourselves: What would they want from our book?; How might they be feeling while reading our book?; What challenges will they be facing? How could our book help them? Such an approach was not without risks. We did not want to rely too heavily on personal anecdotes, or make assumptions that our experiences would be the same as others'. Being part of a team of three was very helpful in this regard. We all had different experiences to draw upon over time in practice, teaching and research; through reflexive discussion and editing each other's writing we were able to challenge each other's assumptions and generalisations (Siltanen, Willis \& Scobie, 2008). However, by using Ruch's (2000) concept of 'practical reflection' we later became more aware of the children and families that were not so present in our thinking; those whom we had 'chosen' to forget, those whose experiences and views challenged or were beyond our beliefs, experiences or expectations or those who had left us with a sense of shame or discomfort about our work with them. 
The idea of past selves impacting on the actions of the self in the present was also a key feature of the experiences of the carers at whom the book was aimed. In Fraiberg, Adelson \& Shapiro's (1975) seminal work, the metaphor of the ghost is used to explain the ways in which past hurts, events and relationships can intrude, unguarded, into the relationship between a parent and infant. The ways in which past experiences of caring and being cared for infiltrate, at an often unconscious level, actions and feelings in the present are central to the process reflection outlined by Ruch (2000). Here, she argues, careful attention must be given to the unconscious aspects of practice and, in particular, the ways in which transference and counter transference can be in play. In the care or support of another, recognising that we may bring previous people and experiences to bear is a vital aspect of social work supervision and of reflective practice.

Hope and hopelessness: systemic issues over which there seems little control

Yip (2009) suggests that the level of harmony and consistency in the relationship between workers' internal experience and the external or contextual factors surrounding them has a significant impact on how at ease they feel with their intervention. It appeared from our analysis that we encountered a parallel process in relation to our writing. All three of us reported a sense of the work we were doing as potentially valuable and as a platform through which we could support the translation of theoretical, empirical and conceptual advances in our field and in our own research into an accessible form which could be readily applied by foster carers and residential staff. However, the current REF agenda meant that we were, in different ways, encouraged to focus scholarly efforts on more formal academic writing. Arguably, there was a disconnect between our internal practicefocused selves and our prescribed academic responsibilities. There also seemed to be a 
wider and more confusing disconnect between the rise of the 'impact' agenda and the reality of what was being valued, encouraged and seen as making 'real' change.

Interestingly, in terms of the process of writing, this appeared to manifest itself in a subversive response rather than a direct challenge to these expectations (Amsler, 2011). As a result, we continued work on the book 'out-of-sight' and kept our reporting of progress to a minimum. We took strength from each other and re-enforced our stance by relating to our practice training and experience. It was only after the writing was completed that we became aware of how we had eachadapted these strategies, avoiding what we later reasoned was our experience of a fruitless battle against the current neo liberal education discourse (Holmwood, 2011; Brewer 2011).

This lead us to wonder about the extent to which similar patterns are evident amongst foster and residential carers. Rather than tackling problematic cultural practices head on (e.g. children being placed regularly as 'emergency admissions' but remaining for extensive periods or being expected to take disproportionate measures to avoid risk) there is an unspoken acceptance of these expectations and, alongside this, a sharing of ways to manage rather than challenge these imposed actions (Colton \& Roberts, 2007; Milligan \& Stevens, 2006).

The subversive stance we identified in ourselves seemed to come more readily when it related to 'the system'. However, we later reflected that we had avoided tackling another challenge which seemed, in retrospect, beyond the power or scope of our abilities yet which had a significant impact on the experience of caring for looked after children. Through 
the lenses of both critical and process reflection (Ruch, 2000) we became aware of the extent to which we had focused in the book on theories and research which emphasised the individual over wider structural issues. Indeed, we realised that whilst structural issues were evidenced in the book, the limited focus on them was absent from our discussion. The decision to minimise them had been entirely unconscious.

Despite being aware of the impacts of, for example, poverty, health, gender on addiction, trauma and recovery, we gave little space to related exploration and did not suggest that readers engage with or feel any responsibility to actively address these structural disadvantages. However, we were very much aware that even at individual or interpersonal levels, such inequalities are increasingly mediated affectively. This led us to consider why we had failed to include these important features of the day-to-day experience of the children that the book accounts for, as well as the carers and practitioners it targets.

Again, we became aware of the parallels between carers' and practitioners' responses to structural disadvantage and our own. Whilst on one level we shared an awareness of the impact of inequalities, both as a contributing cause as well as an ongoing factor in the care of many looked after children, to attempt to address this as a site of change seemed, in retrospect, futile - so much so that we did not even discuss whether or not to incorporate content that directly addressed it. Our focus on the individual as the site for change allowed us to overlook what were often the fundamental causes of many of the children's difficulties, as well as the barriers to effecting positive change.

Whilst structural disadvantage features in training of social workers and to a lesser extent foster carers and residential staff, the move to a more technical/rational model of 
practice has shifted attention away from challenging disadvantage to locating the results of it within the individual (Trevithick, 2012). The radical and community based traditions of social work in the 1970 s and 80 s have become marginalized. Social work as a profession which saw itself as having a role in challenging political and policy decisions has become less so. Cooper (2009, p.41) wonders '... how much reality can we bear to know about?'. This striking statement sums up the sense of overwhelm experienced by practitioners and academics alike when faced not with explaining the causes of behaviours, but what to do about them.

Voice: The legitimacy of our claims and experiences

In recent decades there has been a significant increase in research that attempts to 'give voice' to the views and experiences of those who have traditionally been silenced. This has included looked after children and young people, and those who provide their care (Heptinstall, 2000). In relation to children, voice is often associated with the requirement (based on article 12 of the United Nations Convention on the Rights of the Child (1989) and related policy and legislation at local levels) to consider their views in decisions that affect them (Clarke, Boorman, \& Nind, 2011). More generally, voice is associated with assertion, authenticity, psychological health and power (Taylor, Gilligan and Sullivan, 1995; Gilligan, 1982, 1993). It connects inner and outer worlds (Gilligan, 1982, 1993). Yet there are very real epistemological, methodological and political complexities around 'giving voice' or being informed by children's [or carers'] voices (Alcoff, 1991; Fielding, 2004; Nind, Boorman, \& Clarke, 2012). Moreover, the closeness of researchers to their subjects of study, identified by Cooper (2009) as 'practice-near' research, can allow for real emotional and relational depth in the research process but also carries with it concomitant challenges in 
the form of potential anxiety, confusion and doubt. So it is with practice-near writing. This raises important questions about what makes a writing voice resonant with the reader - a powerful factor in achieving impact - when writing for and about practice.

Our very early discussions about the book's content included a commitment to incorporate, where possible, children and carers' views and experiences in the form of relevant research. Our own authorial voices were also a concern. By considering the act of writing through the lens of process reflection (Ruch 2000), the authenticity of voice emerged as a central theme. Our concerns about how we convinced readers that our work was worth reading whilst at the same time managing our anxieties about being 'good enough' or close enough to practice to have a legitimate voice was something discussed many times. It emerged through this process of reflective analysis that drawing on examples from our own practice, both in our discussions and then ultimately in the writing itself, was a vehicle to authenticate our voice, to suggest to the reader that we had insight into their experience and were enough 'like them' to be worth reading.

This notion of voice translates to the practice context. How do those who provide the day-today direct care and who often are not afforded professional status (and all that goes with it) have their voice heard and recognised? The use of examples, of using the child's own words, of carrying the affect of the child may be strategies employed by direct carers to authenticate their own voices. Indeed, they may regard themselves as the most authentic voice present in decision making as they believe that they know the child best, and often they do. But to what extent do direct care givers feel they have voice? Voice necessarily involves one or more listeners and so must be understood in the context of relational dynamics. Taylor et al. (1995, p.4) illuminate this by describing 'resonant relationships', 
those in which one 'can speak freely and hear her voice clearly resounded as a voice worth listening to and taking seriously - a voice that engages the heart and mind of another and calls forth a response'. In some small way, we hoped that by conjuring the ghosts from our practice experiences and identifying, naming and affirming some of our readers' experiences, we might support them in the risky business of finding and/or exercising their voices. While the parallel is clearer in retrospect, we nonetheless argue that by remaining present with our own sense of questioning and vulnerability, our motivation and effectiveness in supporting carers' voices were sharpened.

\section{Conclusion}

Increasingly, academia is moving toward a technical/rational endeavour where success is measured by output and an explicit, verifiable use of time (Shahjahan, 2015). Similarly, in care practice, an emphasis on the 'tools' of care work rather than the relational experience of caring and being cared for have come to dominate how the 'looked after' experience for children is understood and evaluated (Smith, 2011). Spaces for reflection, for thinking and considering what has shaped and directed thoughts, actions and beliefs have, in both contexts, become gradually sparser and hard to find.

Applying the concept of parallel process to the analysis of the writing activity revealed the way in which many of our writing decisions originated in other parts of the systems in which we operated. Like many social work academics, we occupy academic as well as practice spaces and, as a result, come to take on many of the dynamics at play in both of these social worlds. By employing the concept of parallel process, the extent to which anxieties originating in academic and practice systems were being played out in our 
approach to this work were illuminated. In particular, dominant narratives around voice (who has the 'right' to speak about practice, whose voices do we allow ourselves to hear), our shared sense of hopelessness about many of the systemic challenges children are faced with, our collective avoidance of the structural factors at play, and the resultant sense of overwhelm that can occur when trying to address such factors were highlighted. Whilst it is not the aim of this paper to suggest ways to improve the experience of children and carers of having voice, this process of reflection brought into focus the extent to which our writing, like our practice, was shaped by the encounters and relationships we brought to it. As in practice, so little time is given to reflecting on this and the critical challenges that it brings as a result.

The analytical lenses provided by Ruch (2000) gave structure to the reflective process and forced us to look at aspects of our experiences that hitherto had been subsumed by the attention we had given to 'output'. By systematically considering each of the four types of reflection in turn, a multifaceted tapestry of our own practice began to emerge. Process and critical reflection in particular highlighted the ways in which the complexity of the emotional and feelings aspect of the work had often been sidelined or rendered unconscious. The ways in which current contexts and past experiences shaped our approach to the process of writing as well as the output itself was striking.

To date, neither parallel process nor Ruch's modes of reflection have been applied to academic writing and in particular to writing about, and for, theoretically informed practice. In the course of this paper we have argued that the application of such concepts offers not only a deeper understanding of how knowledge is constructed and exchanged with practitioners, but also contributes to the development of a theoretical understanding of the 
'impact of impact' (Holmwood 2011) and the dangers a neoliberal agenda poses to a critical and reflective academy.

\section{Acknowledgements}

anonymised 


\section{References}

Alcoff, L. (1991). The problem of speaking for others. Cultural Critique, 20 (Winter, 19911992), 5-32.

Alvenson, M., \& Skioldberg, K. (2009). Reflective methodology: New vistas for qualitative research, $2^{\text {nd }}$ edition. London: Sage.

Amsler, S. S. (2011). From 'therapeutic' to political education: The centrality of affective sensibility in critical pedagogy. Critical Studies in Education, 52(1), 47-63. doi: $10.1080 / 17508487.2011 .536512$

Boyd, E.M., \& Fales, A. W. (1983). Reflective learning: key to learning from experience. Journal of Humanistic Psychology, 23(2), 99-117.

Bromberg, P.M. (1982). The supervisory process and parallel process in psychoanalysis. Contemporary Psychoanalysis, 18, 92-111.

Bywaters, P., Brady, G., Sparks, T., Bos, E., Bunting, L., Daniel, B., Featherstone, B., Morris, K. and Scourfield, J. (2015) Exploring inequities in child welfare and child protection services: Explaining the 'inverse intervention law, Children and Youth Services Review, 57, 98-105.

Chatham Clarke, S. (2002). 'Finding the thou in I: Countertransference and parallel process analysis in organizational research and consultation. Journal of Applied Behavioral Science, 38(3), 375-92. 
Clarke, G., Boorman, G., \& Nind, M. (2011). 'If they don't listen I shout, and when I shout they listen': Hearing the voices of girls with behavioural, emotional and social difficulties. British Educational Research Journal, 37(5), 765-780.

Colton, M. \& Roberts, S. (2007). Factors that contribute to high turnover among residential child care staff. Child \& Family Social Work, 12(2), 133-142.

Cooper, A. (2009). Hearing the grass grow: Emotional and epistemological challenges of practice near research. Journal of Social Work Practice: Psychotherapeutic Approaches in Health, Welfare and the Community, 23(4), 429- 442.

Davies, H. Nutley, S. \& Walter, I. (2005) Approaches to assessing the non- academic impact of social science research. Report of the ESRC symposium on assessing the non academic impact of research, URL:http://www.esrc.ac.uk/_images/nonacademic_impact_symposium_report_tcm8-3813.pdf

Doucet, A. (2008). 'From her side of the gossamer wall(s)': Reflexivity and relational knowing. Qualitative Sociology, 31, 73-87.

Featherstone, B (2016) Telling different stories about poverty, inequality and child abuse and neglect, Families, Relationships and Societies , 5 (1), 147-153. 
Fielding, M. (2004). Transformative approaches to student voice: Theoretical underpinnings, recalcitrant realities. British Educational Research Journal, 30(2), 295-311.

Fraiberg, S. Adelson, E. and Shapiro,V. (1975) Ghosts in the Nursery: A Psychoanalytic Approach to the Problems of Impaired Infant-Mother Relationships. Journal of American Academy of Child Psychiatry, 14 (3), 387-421

Gilligan, C. (1982, 1993). In a different voice: Psychological theory and women's development. Cambridge: Harvard University Press.

Goffman, E. (1956). The presentation of self in everyday life. New York: Anchor Books.

Haidt, J. (2001). The emotional dog and its rational tail: A social intuitionist approach to moral judgement. Psychological Review, 108 (4), 814-34.

Heptinstall, E. (2000). Gaining access to looked after children for research purposes: Lessons learned. British Journal of Social Work, 30, 867-872.

HM Government. (2015). Working together to safeguard children; A guide to inter-agency working to safeguard and promote the welfare of children, URL:

https://www.gov.uk/government/uploads/system/uploads/attachment data/fi

le/419595/Working Together to Safeguard Children.pdf 
Hodgson, D. \& Watts, L. (2016). What can moral and social intuitionism offer ethics education in social work? A reflective inquiry, British Journal of Social Work, advanced access, 1-17.

Holmwood, J. (2011) Viewpoint - the impact of 'impact' on UK social science, Methodological Innovations Online, 6 (1), 13-17.

Milligan, I., \& Stevens, I. (2006). Balancing rights and risks: The impact of health and safety regulations on the lives of children in residential care. Journal of Social Work, 6(3), 239-254.

Morrisey, J. \& Tribe, R. (2001). Parallel process in supervision. Counselling Psychology Quarterly, 14 (2), 103-110.

Morton, S. (2014) Creating Research Impact: the roles of research users in interactive research mobilisation, Evidence \& Policy, 11 (1), 35-55.

Moss, P., \& Petrie, P. (2002). From children's services to children's spaces: Public policy, children and childhood. London: RoutledgeFalmer.

Munro, E. (2011) The Munro Review of Child Protection: Final Report. A child- centred system. URL: https://www.gov.uk/government/uploads/system/uploads/attachment data/fi

le/175391/Munro-Review.pdf 
Munro, E. (2011). The Munro review of child protection. Interim report: The child's journey. London: Department of Education. URL:

http//www.gov.uk/government/uploads/system/uploads/attachment data/file /206993/DFE-00010-2011.pdf.

Nind, M., Boorman, G., \& Clarke, G. (2012). Creating spaces to belong: listening to the voice of girls with behavioural, emotional and social difficulties through digital visual and narrative methods. International Journal of Inclusive Education, 13(7), 643-656.

Pardoe, S. (2014) Research Impact Unpacked? A social science agenda for critically analysing the discourse of impact and informing practice, Sage Open, 4 (2), 1-16.

Ruch, G. (2000). Self and social work: Towards an integrated model of learning, Journal of Social Work Practice, 14(2), 99-112.

Scottish Government. (2014). National guidance for child protection in Scotland. URL: http://www.gov.scot/Resource/0045/00450733.pdf

Searles, H.F. (1955). The informational value of supervisor's emotional experiences. Psychiatry, 18, 135-46.

Shahjahan, R.A. (2015) Being 'Lazy' and Slowing Down: Toward decolonizing time, our body, and pedagogy, Educational Philosophy and Theory, 47 (5), 488- 501. 
Siltanen, J., Willis, A., \& Scobie, W. (2007). Seperately together: Working reflexively as a team. International Journal of Social Research Methodology, 11 (1), 45-61.

Smith, M. (2009). Rethinking residential childcare: Positive perspectives. Bristol: Policy Press.

Stolorow, R. (1994). The nature and therapeutic action of psychoanalytic interpretation. In R. Stolorow, G. Atwood \& B. Brandshaft (Eds.), The intersubjective perspective. (pp. 43-56), Northvale, NJ: Jason Arsonson.

Talbot, A. (1990). The importance of parallel process in debriefing crisis counsellors. Journal of Traumatic Stress, 3(2), 265-277.

Taylor, J.M., Gilligan, C., \& Sullivan, A.M. (1995). Between voice and silence: Women and girls, race and relationships. Cambridge: Harvard University Press.

Trevithick, P. (2012). Social work skills and knowledge: A practice handbook. Berkshire: Open University Press. 
Turney, D., Platt, D., Selwyn, J., \& Farmer, E. (2011). Social work assessment of children in need: What do me know? Messages from research. Department for Education. URL: https://www.gov.uk/government/uploads/system/uploads/attachment data/fi le/182302/DFE-RBX-10-08.pdf

Turney, D., \& Ruch, G. (2016). Thinking about thinking after Munro: The contribution of cognitive interviewing to child-care social work supervision and decision-making practices. British Journal of Social Work, 46, 669-685.

Yip, K. (2009) Self-reflection in reflective practice: A note of caution. British Journal of Social Work, 36, 777-788.

Ward, A. (2006). Models of 'ordinary' and 'special' daily living: Matching residential care to the mental health needs of looked after children. Child and Family Social Work, 11(4), 336-346.

Ward, A. (2010). The learning relationship: Learning and development for relationshipbased practice. In G. Ruch, D. Turney \& A. Ward (Eds.), Relationship- based social work: Getting to the heart of practice (pp. 183-198). London: Jessica Kingsley Publishers. 